\title{
Beta- Glukanın Kardiyovasküler Sağlık Üzerine Etkisi
}

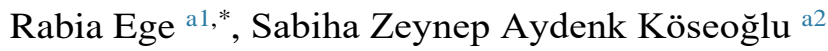 \\ a İstanbul Sabahattin Zaim Üniversitesi, Fen Bilimleri Fakültesi, Beslenme ve Diyetetik Bölümü, İstanbul, Türkiye
}

İstanbul Sabahattin Zaim Üniversitesi Fen Bilimleri Enstitüsü Dergisi (2021) 3 (2): 159-164

https://doi.org/10.47769/izufbed.915997

(iD) ORCID ${ }^{1} 0000-0001-7936-8462 ;{ }^{2} 0000-0001-7954-7014$

\begin{tabular}{|c|c|}
\hline YAYIN BİLGİSİ & ÖZET \\
\hline Yayın geçmişi: & Kardiyovasküler hastalıklar $(\mathrm{KVH})$ dünyada ölüme sebep olan bütün hastalıkların basında yer al \\
\hline Gönderilen tarih: 16 Nisan 2021 & KVH'nın önlenebilir bir hastalık olması sebebiyle üzerinde yapılan çalışmalar önem arz etmektedir. \\
\hline Kabul tarihi: 5 Haziran 2021 & $\begin{array}{l}\text { KVH'yı önleme ve KVH'nın tedavisinde beslenme alışkanlıkları ve yaşam tarzının iyileştirilmesi ön } \\
\text { planda yer almaktadır. Yeterli ve dengeli beslenmenin yanı sıra diyet posasından zengin beslenmenin de } \\
\text { KVH'ya neden olan kandaki; total kolesterol, düşük yoğunluklu lipoproteinler gibi parametrelerin }\end{array}$ \\
\hline Anahtar kelimeler: & $\begin{array}{l}\text { düzeylerini düşürerek hastalığa yakalanma riskini azalttı̆̆ görülmüştür. Yapılan klinik ve deneysel } \\
\text { çalışmalar sonucunda yulaf ve yulaf içeren ürünlerin tüketilmesinin serum kolesterolü ve diğer }\end{array}$ \\
\hline$\beta$-Glukan & $\begin{array}{l}\text { kardiyovasküler hastalık markerleri üzerindeki yararlı etkisi saptanmıştır. Yulafın kolesterol düşürücü } \\
\text { etkisinin, içerdiği } \beta \text {-glukan ve posa ile ilişkili olduğu düşünülmektedir. Amerika Birleşik Devletleri Gıda }\end{array}$ \\
\hline Posa & ve İlaç Dairesi (FDA) 1997'de ,2004 de ise Birleşik Krallık Ortak Sağlık Talepleri Girişimi de (JHCI) yulaf \\
\hline Beslenme & $\begin{array}{l}\beta \text {-glukanın kolesterol düşürücü etkisini onaylamıştır. } \beta \text {-glukanın sadece kolesterol üzerine değil, diyabet, } \\
\text { obezite ve metabolik sendrom gibi kronik hastalıklar üzerine de etkili olarak KVH'nın oluşumunu }\end{array}$ \\
\hline Kardiyovasküler Sağllk & $\begin{array}{l}\text { engellediğine dair çalışmalar da literatürde mevcuttur. Bu çalışmanın amacı da } \beta \text {-glukanın kardiovasküler } \\
\text { sağlık üzerine yapmış olduğu etkileri inceleyerek, sağlıklı beslenmede } \beta \text {-glukana ne ölçüde yer vermemiz }\end{array}$ \\
\hline Kolesterol & $\begin{array}{l}\text { gerektiğini değerlendirerek bilime katkıda bulunmaktır. Son literatürlerde verilen bilgilere dayanarak, } \\
\text { çözünür liflerden } \beta \text {-glukanın KVH'nın korunma ve tedavisi üzerindeki etkisi kanıtlanmış olup, günlük } \\
\text { beslenmede } \beta \text {-glukan içeren besinlerin diyetisyenler tarafindan önerilmesinin doğru olabileceği } \\
\text { belirlenmiştir. }\end{array}$ \\
\hline
\end{tabular}

\section{The Effect Of Beta Glucan On Cardiovascular Health}

\begin{tabular}{l}
\hline ARTICLE INFO \\
\hline Article history: \\
Received: 16 April 2021 \\
Accepted: 5 June 2021 \\
\hline Key words: \\
B-Glucan \\
Fiber \\
Nutrition \\
Cardiovascular Health \\
Cholesterol
\end{tabular}

\begin{abstract}
Cardiovascular diseases (CVD) are among the leading diseases that cause death in the world. Since CVD is a preventable disease, studies on it are important. Improving dietary habits and lifestyle are in the foreground in the prevention and treatment of CVD. In addition to adequate and balanced nutrition, nutrition rich in dietary fiber also causes CVD in the blood; It has been observed that it reduces the risk of developing the disease by lowering the levels of parameters such as total cholesterol and low density lipoproteins. As a result of clinical and experimental studies, the beneficial effect of consuming oats and products containing oats on serum cholesterol and other cardiovascular disease markers has been determined. The cholesterollowering effect of oats is thought to be related to the $\beta$-glucan and pulp it contains. The United States Food and Drug Administration (FDA) approved the cholesterol-lowering effect of oat $\beta$-glucan in 1997 and the United Kingdom Joint Health Claims Initiative (JHCI) in 2004. There are also studies in the literature that B-glucan prevents the formation of CVD not only on cholesterol but also on chronic diseases such as diabetes, obesity and metabolic syndrome. The aim of this study is to examine the effects of $\beta$-glucan on cardiovascular health and to contribute to science by evaluating to what extent we should include $\beta$-glucan in healthy diets. Based on the information given in the recent literature, the effect of $\beta$-glucan, one of the soluble fibers, on the prevention and treatment of CVD has been proven, and it has been determined that it may be correct to recommend foods containing $\beta$-glucan in daily nutrition by dieticians.
\end{abstract}

\section{Giriş}

Kardiyovasküler hastalıklar (KVH), her y1l yaklaşı 17,9 milyon kişinin ölümüne sebep olan dünya çapında en önemli sağlık sorunlarının başında gelir. Kardiyovasküler hastalıklar hem kalp hem de kan damarlarındaki anormallikleri ihtiva eden bir kompleks sorunlar bütünüdür. Koroner kalp hastalığının yanı sıra serebrovasküler hastalıklar ve romatizmal kalp hastalıkları da kardiyovasküler hastalıklara örnektir. KVH sebebiyle gerçekleşen beş ölümden dördü kalp krizi ve felçten kaynaklanmaktadır ve bu ölümlerin \% de 33'ü yaşı 70'den küçük olan bireylerde gerçekleşmektedir. (World Health Organization, 2019). KVH'nın 
dünya çapında uzun bir müddet başlıca ölüm sebeplerinde ilk sırada yer alacağı düşünülmektedir. Gelişmekte olan ülkelerde $\mathrm{KVH}$ sebebiyle gerçekleşen ölümlerde artış görülürken, gelişmiş olan ülkelerde bu oran azalmaktadır. Fakat nüfusun artış1 ve yaşam süresinin uzamış olması, KVH'nın prevelansını arttırmaktadır (Türkiye Halk Sağlığı Kurumu, 2015). KVH görülme riski olan kişilerde; Obezite, Hipertansiyon, Hiperlipidemi, Hiperglisemi gibi hastalıklar ayrıca KVH'ya eşlik edebilmektedir. KVH nedeniyle gerçekleşen ölümleri en aza indirmek için erken teşhis ve tedavinin acil olarak uygulanması çok önem taşımaktadır (World Health Organization, 2019). KVH görülmesinde etyolojik olarak bir çok faktör bulunmaktadır. Bu faktörlerden en başta gelenlerden birinin, düşük yoğunluklu lipoprotein (LDL) kolesteroldeki artış olduğu olduğu düşünülmektedir. Mendel'in randomizasyon deneyleri ve birçok müdahale çalışmaları, plazma LDL kolesterol seviyelerindeki artışların kardiyovasküler riskle ilişkili olduğunu göstermiştir (Visioli \& Poli , 2019).

Kalp ve damar hastalıklarından korunmada, Dünya Sağlık Örgütünün çalışmalarına göre; obezite, hipertansiyon ve sigara kullanımı gibi faktörlerin kontrol edilmesi durumunda, görülme sıklığında \%50 kadar azalma olabileceği saptanmıştır (Türkiye Halk Sağlığı Kurumu, 2015).

Kalp damar hastalıklarından korunmada, diğer faktörlerin yanı sıra sağlıklı beslenmenin rolü yadsınamaz. Literatürdeki birçok çalışma diyetteki yağ oranının ve türünün KVH görülme riskini doğrudan veya dolaylı yollarla etkilediğini ispatlamıştır. Yeterli ve dengeli beslenmenin kalp damar hastalıklarından korunmada etkili olduğu gibi sağlıksız beslenmenin de bu hastalıkların oluşma riskini arttıracağı bilinmektedir. Doymuş yağ asitlerini içeren yağlar ve trans yağlar gibi yağ çeşitlerinin kullanımı, tuz ve işlenmiş besinlerin aşırı tüketimi; diyet lifinin ve antioksidan öğelerin alımının yetersiz olması ve tütün ürünleri kullanımı bu riski arttıran başlıca sebeplerdendir (Vetvicka, 2019).

Beslenme müdahaleleri, kalp damar hastalıklarının çeşitli risk faktörlerini azaltan, koruyucu ve kolay uygulanabilir bir strateji olarak görülmektedir. KVH için sağlıklı besin grupları; meyve ve sebzeler ve içerdikleri; lif, vitaminler, polifenoller ve sağlıklı yağlar (sızma zeytinyağı, bitkisel yağlar, fındık, yağlı balık) olarak bilinip, ayrıca sodyumdan düşük besinlerle beraberce $\mathrm{KVH}$ riskini azaltmaktadırlar (Visioli \& Poli , 2019). Yeterli ve dengeli beslenmenin yanında diyet posasının tüketimiyle $\mathrm{KVH}$ görülme riski arasında ters korelasyon bulunmaktadır (Vetvicka, 2019).

\section{Diyet Posası}

Diyet posası, bitkilerdeki sindirilemeyen karbonhidratlardır. Diyet posası çözünme durumuna göre, çözünür veya çözünmez posa olarak sınıflandırabilir. Selüloz, hemiselüloz ve lignin çözünmez lif çeşitlerinden olup; Pektin, guargum, psyllium, beta glukan ise çözünür lif sınıfına girerler. Koroner kalp hastalıklarının önemli bulgularından biri olan hiperkolesterolemi diyetlerinde çözünür lif tüketim miktarlarına dikkat edilmesi önem taşımaktadır (Ho, 2016). Dünya Sağlık Örgütü'nün tavsiyeleri, sağlıklı bir diyetin 25 gr'dan fazla diyet lifi içermesi gerektiğini (Gerschenson, 2021) ve çoğu Avrupa ülkesinin günde 25 ila $30 \quad$ gr arasında lif önerdiğini belirtmektedir (Stephen, 2017). Çözünür lifin kaynaklarından olan beta glukanın bulunduğu besinlerden biri de yulaftır ve yulaftaki çözünür lif oranının büyük bir kısmını oluşturmaktadır. Yapılan çalışmaların çoğunda, günlük beslenmede çözünür posa miktarının arttırılmasının toplam kolesterol ve LDL kolesterol seviyelerine olumlu katkıları olabileceği bildirilmektedir
(Ho, 2016).

\section{Beta Glukan}

$\beta$-glukan; arpa, yulaf, çavdar benzeri tahıl tanelerinin ve bazı bakteri, maya ve mantarların, hücre duvarında, nişasta olmayan, aralarında $\beta$-glikozidik bağlar bulunan D-glukoz monomerlerinden meydana gelen bir polisakkarit çeşitidir ( $\mathrm{Du}, 2019)$.

Yulaf ve arpanın beta glukan içerikleri yaklaşık olarak; \%2,3- 8,5 (yulaf) ile \%3- 11 (arpa) arasındadır (Myriam M.-L. Grundy, 2018). Tahıl taneleri aralarında $\beta$-glukan miktarı en fazla olan yulaftır. Yulaf kepeğinin $\beta$-glukan içeriği $\% 7$ oranlarındadır. Arpa $\% 5$ oranında kuru yulafla aynı oranda, buğday ve çavdar ise $\% 2 \beta$ glukan ihtiva eder (Du, 2019).

$\beta$-glukan gibi çözünür liflerin etki mekanizmalarını tam olarak anlayabilmek için birkaç hipotez ortaya konmuştur. Bunlar arasında en kabul gören hipotez, liflerin bağırsakta viskoziteleri sebebiyle kolesterol, safra asitleri ve diğer yağların ekspresyonunu arttırdığı şeklindedir. $\beta$-glukanın en etkili olanının, yüksek molekül ağırlıklı fraksiyonunun olduğu düşünülmektedir. Ayrıca, prebiyotik etkisi de göz önüne alınarak, emiliminden sonra kısa zincirli yă asidi (SCFA) sentezinin artmasına yol açtığı belirlenmiştir. Karaciğerde kolesterol sentezinin inhibitörü olarak rol alır, yüksek dozajdaki beta glukan, öğün sonrası glisemik yanıtı da iyileştirebilmektedir (Visioli \& Poli , 2019). Yulaf verilmesinin ardından barsaklarda artan viskozitenin; glikoz, kolesterol ve safra asitlerinin geri emilimini inhibe etmesi ile, diyabet ve kalp damar hastalıklarını oluşturan kan parametrelerinden; glikoz, insülin ve kolesterol düzeylerinin düşürüldüğü ( $\beta$-glukan içeren viskoz ve çözünür diyet posaları ile) bilinmektedir (Vetvicka, 2019). B-glukanların, serum kolesterolünü azaltmasının yanı sıra kanseri, hiperglisemiyi, inflamasyonu önleme ve immun sistemini iyileştirme gibi sağ bulunmaktadır (Junying Bai, 2019).

\subsection{Beta Glukanın Yapısı}

Kimyasal olarak $\beta$-glukanlar, maya ve algler dahil olmak üzere belirli mikroorganizmaların hücre duvarının yapısal bileşiklerini ve yulaf ve buğday gibi mantarlar ve tahıllar dahil olmak üzere belirli yapısal bileşiklerini oluşturan nişasta olmayan heterojen polisakkaritlerdir. $\beta$-glukanlar glikoz moleküllerinin bağlanma şekillerine göre farklı yapılarda olurlar ( Şekil 1). $\beta$-glukan, mantar, maya, yulaf, arpa ve bazı bakteriler gibi çeşitli kaynaklarda bulunmaktadır. Maya ve mantarların hücre duvarlarında bulunan $\beta$ glukanlar az sayıda 1,6 $\beta$ bağlı dallar ile 1,3 $\beta$ bağlı glikopiranosil kalıntılarından oluşurken, arpa ve yulaf hücre duvarlarındaki $\beta$ glukanlar 1,3 ve $1,4 \beta$ bağlı glikopiranosil kalıntısı içeren dalsız $\beta$ glukanlardır. Bakterilerde ise $1,3 \beta$ bağlı glikopiranosil kalıntısı içeren dalsız $\beta$-glukanlar bulunur. Tahıl kaynaklı $\beta$-glukanlar suda çözünürlerken, maya ve mantarlardan elde edilen $\beta$-glukanlar suda çözülmezler. Suda çözünen ve çözünmeyen $\beta$-glukanların etki mekanizmaları arasında farklılıklar vardır ( $\mathrm{Du}, 2019)$.

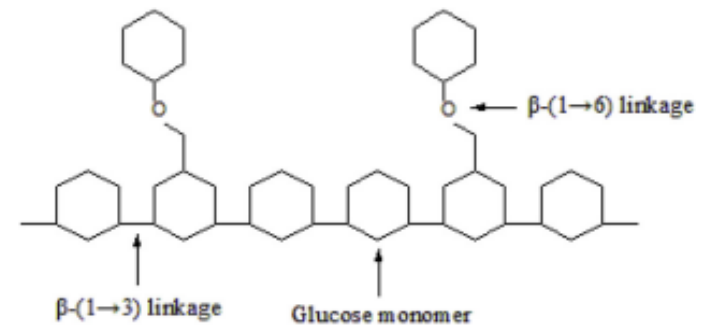

Şekil 1. $\beta$-glukanın 1,3 ve 1,6 $\beta$ dallı yapısı (Junying Bai, 2019) 
$\beta$-glukanların fonksiyonları yapılarına göre değişiklik gösterir. $\beta$ glukanların bağışıklık sistemini güçlendirme ve kanser önleme fonksiyonları yapısal özelliklerinden kaynaklanır. $\beta(1,6)$ ve $\beta(1,3)$ dalları bağlı olan $\beta$-glukanın, immuno modülasyon ve sitokin sitümilasyonu özellikleri vardır. Dallanma, bağlantı şekli ve çözünürlüğüne göre bağışıklığı güçlendirici gibi önemli rollere sahip olup, çözünürlük oranlarına göre güçlü olan $\beta$-glukanın sitokin üretimine sebep olabileceği gösterilmiştir (Jayachandran, Chen, \& S, 2018).

\subsection{Beta Glukanın Etki Mekanizması}

$\beta$-glukanın lif yapısının özelliğine dayanarak, barsak içeriğinin viskozitesinin artmasıyla safra asidinin tekrar emilimini uyardığı ve kolesterolü düşürmede bu şekilde etki gösterdiği belirlenmiştir. Viskozitenin ise barsaktaki çözünürlük ve molekül ağırlığına bağlı olarak değişebileceğini, bunun yanı sıra yulaf içeren ürünlerdeki $\beta$ glukanın lipoprotein profili üzerinde, birbirini desteklemeyen sonuçlarının nedeninin, yalnızca $\beta$-glukan molekül ağırlığındaki farklılıklardan kaynaklanabileceği düşünülmüştür. Birbirini desteklemeyen sonuçların varlığının nedenini araştırmak amacıyla yapılan çalışmalar, olumsuz sonuçların yulaf ürünlerinde çözünürlüğün az olmasına ve ayrıca ürünün içerisindeki $\beta$-glukanın molekül ağırlığının düşük olmasına bağlı olduğunu rapor etmektedirler ( $\mathrm{Du}, 2019)$.

\subsubsection{Beta Glukanın Kolesterol Düşürücü Mekanizmaları}

KVH dan korunmada ve oluşmuş hastalı̆̆ın tedavisinde beslenmede yer alması gereken çözünür posa içerisinde bulunan $\beta$-glukanların kolesterol düşürücü çeşitli mekanizmaları bulunmaktadır. $\beta$ glukanların posaya benzer şekilde, bağırsağın mukozal yüzeyinde bir jel oluşturabileceği bilinmektedir. Bu jel yapı, safra tuzlarının emilimini inhibe ederek karaciğerde safra tuzu sentezini uyarmaktadır. Artan safra tuzları ise, dolaşımdaki kolesterolün kullanımını aktive ederek kandaki seviyelerini düşürmektedir ( Şekil 2).

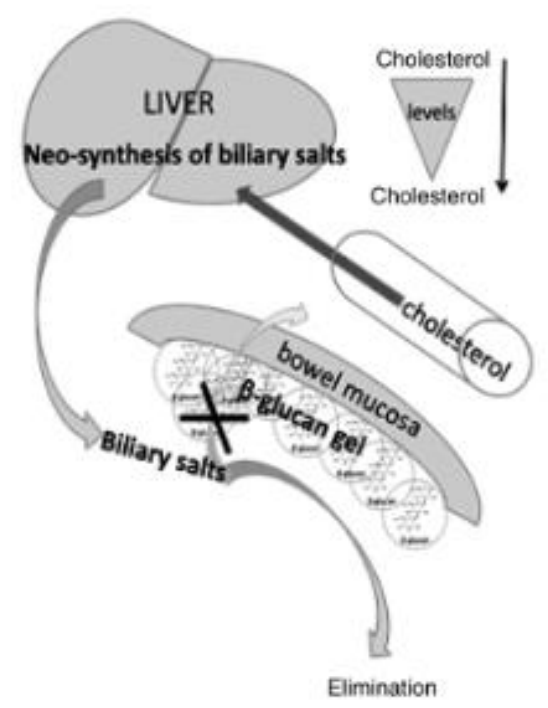

Şekil 2. $\beta$-Glukanın Kolesterol Düşürücü Mekanizması (Sima,
Ayrıca $\beta$-glukanın çeşitli yollardan da kolesterolü düşürdüğü belirlenmiştir;

1-Gastrointestinal sistemde viskozitenin artışı ile glikozun emiliminin azalıp, insülinin konsantrasyonu ve hepatik stimüle aktivitesinin azalarak hepatik koleterol seviyesini düşürmesi,

2-Diyet kolesterolünün bağırsaktan emiliminin azalması,

3-Karaciğerdeki safra asitlerinin kolesterolü dönüştürerek, serum kolesterol seviyesini düşürmesi,

4-Safra asitlerinin yeniden emilip, karaciğere dönmesi (Susan A. Joyce, 2019)

\subsection{Beta Glukanın Kaynakları}

$\beta$-glukanın tahıllardan yulaf ile alımı diğer tahıl ürünlerine göre daha fazla tercih edilmektedir. Literatürde de yulaf ile yapılan çalışmalar sayıca daha fazladır. Yulaf bileşenlerini kepek, saflaştırılmış $\beta$ glukan ve un olarak sıralayabiliriz. Amerikan Tahıl Kimyası Birliğinin açıklamalarına göre, yulaf kepeğinin içerisinde, minimum \%5,5 oranında $\beta$-glukan bulundurma kararı alınmıştır. Ancak, bu karara uygun olabilen b-glukan oranını içeren yulaf kepekleri sınırlıdır. $\beta$-glukan içeren yulaflar, kahvaltılık gevrekler (tahıllı bisküviler, müsli ve granola), bisküvi ve kurabiyeler, mısır gevreği çubukları, ekmek ve kekler gibi ürünler içerisinde bulunabilmektedir (Grundy, 2018).

Glukanlara sülfasyon, karboksimetilasyon ve oksidasyon gibi kimyasal yöntemler ve radyasyon, mikrodalgalar ve 1sıtma gibi fiziksel yöntemler dahil olmak üzere çeşitli yaygın modifikasyon yöntemleri uygulanmıştır (Çizelge1). Kimyasal işlemlerden olan sülfatlama, mayada bulunan $\beta$-glukana uygulandığında bağışıklığın güçlendiği belirlenmiştir (H. Wang, 2015). Yulaf $\beta$-glukanı asetilasyona maruz bırakıldığında ise safra asidi bağlama kapasitesinin arttığ1 görülmüştür (N. L. de Souza, 2015). Bir yulaf türü olan Avenia Sativa $\beta$-glukanına uygulanan fiziksel işlemlerden olan Gama 1şınlaması sonucunda antioksidan, antikanser ve hipoglisemik aktivite fonksiyonları saptanmıştır (P. R. Hussain, 2018). 
Çizelge 1. ß-glukanın modifikasyonları ve ürünlerinin fizyolojik işlevleri (Junying Bai, 2019)

\begin{tabular}{|c|c|c|c|c|c|}
\hline Tür & Yöntem & Nesne & Kaynaklar & Fonksiyonlar & Referanslar \\
\hline \multirow{8}{*}{ Kimyasal modifikasyon } & Sülfatlama & $(1 \rightarrow 3)(1 \rightarrow 6)$ - $\beta$-D-glukan & Russula virescens & Antitümör & (Z. Sun, 2009) \\
\hline & Sülfatlama & $(1 \rightarrow 3)(1 \rightarrow 6)$ - $\beta$-D-glukan & Maya & Bağışıklığın iyileştirilmesi & (M. Wang, 2016) \\
\hline & Karboksimetilasyon & $(1 \rightarrow 3)(1 \rightarrow 6)$ - $\beta$-D-glukan & Lasiodiplodia theobromae & Antioksidasyon & (F.Y. Kagimura, 2015) \\
\hline & Karboksimetilasyon & $(1 \rightarrow 3)(1 \rightarrow 6)$ - $\beta$-D-glukan & Pleurotus yumru rejimi & Anti-tümör & (Zhang M. , 2004) \\
\hline & karboksimetilasyon-sülfasyon & $(1 \rightarrow 3)(1 \rightarrow 6)$ - $\beta$-D-glukan & Poria cocos & İmmünoaktivite & (H. Wang, 2015) \\
\hline & Asetilasyon & $(1 \rightarrow 3)(1 \rightarrow 4)$ - $\beta$-D-glukan & Yulaf & $\begin{array}{l}\text { Safra asidi bağlama kapasitesinin } \\
\text { artırılması }\end{array}$ & (N. L. de Souza, 2015) \\
\hline & Fosforilasyon & $(1 \rightarrow 3)(1 \rightarrow 6)$ - $\beta$-D-glukan & maya Saccharomyces cerevisiae & immün sistemi uyarıcı aktivite & (F. Shi, 2014) \\
\hline & Asit degradasyonu & $(1 \rightarrow 3)(1 \rightarrow 6)$ - $\beta$-D-glukan & Maya & Bağışıklık düzenleyici & (Y. Ishimoto, 2018) \\
\hline \multirow{5}{*}{ Fiziksel modifikasyon } & Mikrodalga & $(1 \rightarrow 3)(1 \rightarrow 4)$ - $\beta$-D-glukan & Hordeum vulgare $\mathrm{L}$ & Antioksidasyon artırıcı & (M. Ahmad, 2016) \\
\hline & Kurutma & $(1 \rightarrow 3)(1 \rightarrow 4)$ - $\beta$-D-glukan & bira mayası & İmmünoaktivite & (J. Liepins, 2015) \\
\hline & Ultrason & $(1 \rightarrow 3)(1 \rightarrow 6)$ - $\beta$-D-glukan & Cordyceps sinensis $\mathrm{Cs}-\mathrm{HK} 1$ & Nemlendirici & (X. Chen, 2014) \\
\hline & Gama ışınlaması & $(1 \rightarrow 3)(1 \rightarrow 6)$ - $\beta$-D-glukan & Maya & Bitki büyümesi destekleyici & (Q. Luan le, 2014) \\
\hline & Gama ışınlaması & $(1 \rightarrow 3)(1 \rightarrow 4)$ - $\beta$-D-glukan & Avena sativa & $\begin{array}{l}\text { Antioksidasyon, antikanser, } \\
\text { hipoglisemik aktivite }\end{array}$ & (P. R. Hussain, 2018) \\
\hline
\end{tabular}

\section{Beta Glukan Konusunda Yapılan Çalışmalar}

Kan kolesterol seviyelerindeki azalma kronik kalp hastalığı gibi kardiyovasküler hastalıkların önlenmesi ve tedavisinde büyük önem taşır. Bu konuda yapılan tüm çalışmalarda $\beta$-glukanın safra asitleri üzerine etkisiyle ve bahsedilen etki mekanizmaları ile kolesterol seviyesini düşürdüğü düşünülmektedir. Ayrıca safra asitlerinin faydalı miktarda salgılanmasını sağlamaktadır (Ghaffarzadegan, 2018), (Mackie et al., 2016), (Gunness, 2017).

Hindistan'da yapılan bir çalışmada hafif hiperkolesterolemik Asya Yerlilerinde yulaf tüketiminin lipit parametreleri üzerindeki etkileri incelenmiştir. Müdahale grubunda hastalara günde iki kez yulaf lapası ve upma (Baharatlar ve sebzeler ile yulaftan kalın bir yulaf lapası) şeklinde $70 \mathrm{~g}$ yulaf verilmiş, lipid parametreleri başlangıçta ve 4 haftalık müdahaleden sonra değerlendirilmiştir. Dört haftalık müdahalede; $70 \mathrm{~g}$ yulafla birlikte günde $3 \mathrm{gr}$ çözünür lif tüketiminin, hiperkolesterolemik Asya yerlilerindeki lipit parametreleri, özellikle toplam kolesterol ve düşük yoğunluklu lipoprotein kolesterol üzerinde faydalı etkilere yol açtı̆̆ saptanmıştır. Bu çalışmada yulaf lifinin kolesterol düşürücü etkisini daha iyi belirlemek için daha uzun bir müdahale süresi boyunca büyük ölçekli çalışmalara ihtiyaç olduğu sonucuna varılmıştır (Gulati, Misral, \& Gulati, 2017).

Ho ve arkadaşları, 615 sağlıklı ve hiperkolesterolemik katılımcıyı içeren 14 çalışmanın sistematik bir incelemesi ve meta-analizini yayınlamış, arpa $\beta$-glukanlarının LDL (düşük yoğunluklu lipoprotein) kolesterolü düşürdüğü ancak HDL (yüksek yoğunluklu lipoprotein) kolesterol seviyelerini düşürmediği görülmüştür. Ortalama 6.5 ve $6.9 \mathrm{~g}$ / gün $\beta$-glukan dozu ile desteklenen diyetler, kontrol diyetlerine kiyasla LDL ve HDL kolesterol olmayan kolesterol seviyelerini \%7 düşürmüştür (Ho, 2016).

Yirmi altı sağlıklı gönüllü üzerinde gerçekleştirilen pilot çalışmada, gönüllülerin günlük beslenme planına, arpa $\beta$-glukanı $(3 \mathrm{~g} / 100 \mathrm{~g})$ ile zenginleştirilmiş makarna dahil edilerek 2 aylık diyet tedavisi uygulanmıştır. Kan ve idrar rutin parametreleri, diyet tedavisinden önce ve sonra değerlendirildiğinde beslenme tedavisinin, beklendiği gibi LDL ve toplam kolesterolü önemli ölçüde düşürdüğü gözlenmiştir (Cosola, 2017).

$\beta$-glukanın viskozitesinden kaynaklandığı düşünülen antihipertansif etkisi birçok çalışmada karşımıza çıkmaktadır. Tansiyon düşürücü etkisini, viskozitesi sebebiyle kilo kaybına yol açma suretiyle gerçekleştirdiği belirlenmiştir (Khan, 2018).

Tahıldaki $\beta$-glukanların, diyabetin önlenmesinde, postprandial kan glukozu ve insülin seviyelerinin düzenlenmesi yoluyla etkilerini gösterdikleri bulunmuştur. Yapılan bir çalışma, düşük seviyede bile tüketilen yulaf $\beta$-glukanın hem glisemi hem de insülini azalttığını göstermiştir (Ekström, 2017) (AbuMweis, 2016).

$\beta$-glukanların bağırsak mukusu ile etkileşimi ile tahıl $\beta$ glukanlarının, postprandial kan glukozu ve insülin düzeylerinin düzenlenmesinde etkili görev aldıkları görülmüştür (Mackie, 2016).

Başka bir çalışmada ise altı ay boyunca $\beta$-glukan lifleri ile zenginleştirilmiş düşük nişastalı ekmek alan grup ile, beyaz ekmek verilen kontrol grubunun karşılaştırılmasında; kontrol grubundan farklı olarak müdahale grubunda postprandiyal ve total plazma glukozunun azaldığı görülmüştür. TİP 2 diabetes mellitusta; $\beta$ glukan eklenmiş ekmeğin düzenli alımı ile kan şekerini kontrol etmek amacıyla kullanılan ilaçlara ek olarak orta ila uzun vadeli glisemik kontrolü iyileştirebileceği belirtilmiştir. (Tessari \& Lante, 2017)

$\beta$-glukan, hücre duvarı içinde karmaşık bir matris oluşturmak için proteinleri ve nişastayı kapsayabilecek ağ benzeri bir doğal yapıda bulunmaktadır. Bu matris, enzimin erişilebilirliğini azaltarak nişasta sindiriminin azalmasına ve postprandial glisemik yanıtın azalmasına neden olabilmektedir (Zhang J. L., 2017).

Yulaf $\beta$-glukanının yüksek viskozitesi, normalde emici bağırsak epitel hücrelerinde glikoz alımına karşı, glikoz taşıma proteini olan 1 (SGLT1) ve taşıyıcı 2'(GLUT2) nin ekspresyonunu etkileyerek fiziksel bir engel olarak da önemli bir rol oynayabilmektedir (Abbasi, 2016).

Obezitenin fazla yağ alımı ve düşük lif alımıyla ilgisi olduğu düşünülmektedir. Bitkisel $\beta$-glukanlar posa olarak, obeziteyle ilgili biyokimyasal parametrelerde, karaciğer yağlanmasında ve adipoz dokunun büyüklügünde etkin role sahiptir. Arpadan elde edilen $\beta$ glukanın visseral yağ birikimine engel olduğu bilinmektedir (Aoe, 2017).

Obez kadınlar üzerine yapılan bu çalışmada bir grupta sadece kalori kısıtlamasına gidilirken diğer grupta aynı kalori değerleri ile beta glukan kaynağı yulaf eklenmiştir. Çalışmanın sonunda her iki grupta da kilo kaybı gerçekleşmiş olup, vücut kompozisyonlarında anlamlı fark bulunmuş ancak gruplar arasında farklılık saptanmamıştır. Kan 
parametrelerinde ise anlamlı sonuç belirlenmemiştir (Şahin, 2018).

$\beta$-glukanların antinflamatuar etkisi de oldukça önem taşımaktadır. Örneğin, $\beta$-glukan, hasarlı reseptörlerin ekspresyonunu inhibe ederek ve bağırsak geçirgenliği ile bağlantı kurarak proteinlerin ekspresyonunu arttırır ve hasarlı lezyonlarda ve barsak bariyerinde mukozada dekstran sodyum sülfatın neden olduğu deformasyonları iyileştirir. (Han F., 2017)

$\beta$-glukanın, apoptotik hücrelerin makrofaj aracılı fagositozunun baskıladığı, ve PKC- $\beta$ II translokasyonunun inhibisyonunda etkili olduğu bildirilmektedir. (Sekiguchi, 2016).

Yapılan diğer bir çalışmada ise, fosforilasyonun $\beta$-glukanın antioksidan özelliği üzerine etkileri ele alınmıştır. Fosforilize edilmiş $\beta$-glukanın, zaman içerisinde; lipit peroksidasyonuna, yaşlanmaya, kardiyovasküler sağlık sorunlarına ve tümörlere neden olabilen çeşitli serbest radikallerini temizlediği ve serum, karaciğer, beynin Süperoksit Dismutaz ve katalaz içeriğini anlamlı oranda yükselttiği, karaciğer ve beyindeki malondialdehyde (MDA) seviyelerini önemli miktarda yükselttiği görülmüştür. Bu çalışmanın sonucu olarak fosforilize edilen $\beta$-glukanın antioksidan olarak kullanılabileceği gösterilmiştir. (Meia, Tanga, \& Huanga, 2020) .

\section{Sonuc}

$\beta$-glukanın metabolik hastalıklar, enfeksiyon hastalıkları ve immun sistem üzerine etkisi mevcut literatürler 1şığında incelenmiştir. Sonuç olarak başta kan Total kolesterol, LDL kolesterol seviyelerini düşürücü etkisi olduğu, ayrıca glisemik yanıtı düzenlemesinin yanısıra antinflamatuar ve antioksidan işlevi bulunduğu çeşitli çalışmalarla kanıtlanmıştır. Resmî Gazetede, Türk Gıda Kodeksi Beslenme ve Sağlık Beyanları Yönetmeliği'nde $\beta$-glukanların normal kan kolesterol düzeyinin korunmasına katkıda bulunduğu yayınlanmıştır (T.C. Resmî Gazete, 26 Ocak 2017, sayı 29960). İnsan sağlığının korunması ve hastalıkların tedavisi üzerine olumlu etkileri dolayısıyla, diğer antioksidanlar gibi supleman olarak veya tıbbi beslenme tedavisinde yer alacak şekilde tüketimi uygun olabilir. Bu konuda sağlık profesyonellerinin $\beta$-glukanın olumlu özelliklerini bilerek kişilere önerilerde bulunması gerekir.

\section{Kaynaklar}

Abbasi, N. N. (2016). Oat $\beta$-glucan depresses SGLT1- and GLUT2mediated glucose transport in intestinal epithelial cells (IEC-6). Nutrition Research, 541-552.

AbuMweis, S. S. (2016). Effectof barleyß-glucan on postprandial glycaemic response in the healthy human population: A meta-analysis of randomized controlled trials. Journal of Functional Foods, 329-342.

Aoe, S. A. (2017). Effects of high B- Glucan barley on visceral fat obesity in Japanese individuals: A randomized, doubleblind study. Nutrition, 1-6.

Cosola, C. D. (2017). Beta-Glucans Supplementation Associates with Reduction in P-Cresyl Sulfate Levels and İmproved Endothelial Vascular Reactivity in Healthy Individuals . PLoS ONE, 12.

Du, B. M. (2019). A Concise Review on the Molecular Structure and Function Relationship of $\beta$-Glucan. International journal of molecular sciences, 4032.

Ekström, L. M. (2017). Oat $\beta$-glucan containing bread increases the glycaemic profile. JournalofFunctionalFoods, 106-111.
F. Shi, J. K. (2014). Mechanochemical phosphorylation and solubilisation of $\beta$-D-glucan from yeast Saccharomyces cerevisiae and its biological activities. PLoS One, 1-9.

F.Y. Kagimura, M. d. (2015). Biological activities of derivatized Dglucan: A review . International Journal of Biological Macromolecules, 588-598.

Gerschenson, L. R. (2021). Dietary Fibre. C. M. Galanakis içinde, Food Bioactives and Health (s. 119-157). Vienna, Austria: Springer.

Ghaffarzadegan, T. Z. (2018). ). Effects of barley variety, dietary fiber and $\beta$-glucan content on bile acid composition in cecum of rats fed low- and high-fat diets. Journal of Nutritional Biochemistry, 104-110.

Grundy, M. M. (2018). Processing of oat: the impact on oat's cholesterol lowering effect. Food \& Function, 13281343.

Gulati, S., Misral, A., \& Gulati, R. (2017). 3. Effects of $3 \mathrm{~g}$ of soluble fiber from oats on lipid levels of Asian Indians - a randomized controlled, parallel arm study. Health and Disease, 71.

Gunness, N. M. (2017). Oat $\beta$-glucan lowers blood cholesterol by restricting its intestinal absorption and decreasing bile acids levels. JNIM , 80.

H. Wang, J. M. (2015). In vivo immunological activity of carboxymethylated-sulfated $(1 \rightarrow 3)$ - $\beta$-D-glucan from sclerotium of Poria cocos. International Journal of Biological Macromolcules, 511-517.

Han F., F. H. (2017). Oraladministrationofyeast $\beta$-glucan ameliorates inflammation and intestinal barrier in dextran sodium sulfate-induced acute colitis. Journal of Functional Foods, 115-126.

Ho, H. S.-Y. (2016). The Effect of oat B-Glukan on LDL_cholesterol, non-HDL_cholesterol and apob for CVD risk reduction:A systemic review and metaanalysis of randomised-controlled trials. British Journal of Nutrition , 1369-1382.

J. Liepins, E. K. (2015). Drying enhances immunoactivity of spent brewer's yeast cell wall $\beta$-D-glucans. Journal of Biotechnology, 12-16.

Jayachandran, M., Chen, J., \& S, S. (2018). A critical review on the impacts of beta-glucans on gut microbiota and human health. Journal of Nutrition Biochemistry, 101-110.

Junying Bai, Y. R. (2019). Physiological Functionalities and Mechanisms of Beta Glucans. Trends in Food Science \& Teknology, 57-66.

Khan, K. J. (2018). The effect of viscous soluble fiber on blood pressure: A systematic review and meta analysis of randomize controlled trials. Nutrition Metabolism and Cardiovaskuler Disease.

M. Ahmad, A. G. (2016). Germination and microwave processing of barley (Hordeum vulgare L) changes the structural and physicochemical properties of $\beta$-d-glucan \& enhances its antioxidant potential. Carbonhydrate Polymers, 696702 .

M. Wang, L. Z. (2016). Improvent of immune responses to influenza vaccine (H5N1) by sulfated yeast beta-glucan. International Journal of Biological Macromolecules, 
203-207.

Mackie, A. B. (2016). Roles for dietary fibre in the upper GI tract: The importance of viscosity. Food Research International, 234-238.

Meia, X., Tanga, Q., \& Huanga, G. e. (2020). Preparation, structural analysis and antioxidant activities of phosphorylated $(1 \rightarrow 3)-\beta$-D-glucan. Food Chemistry.

Myriam M.-L. Grundy, A. F. (2018). Processing of Oat: The Impact on Oat's Cholesterol Lowering Effect. Food and Function.

N. L. de Souza, J. B. (2015). Functional, thermal and rheological properties of oat $\beta$-glucan modified by acetylation. Food Chemistry, 243-250.

P. R. Hussain, S. A. (2018). Structural characterization and evaluation of antioxidant, anticancer and hypoglycemic activity of radiation degraded oat (Avena sativa) $\beta$ glucan. Radiation Physics and Chemistry, 218-230.

Q. Luan le, N. H. (2014). Radiation degradation of $(1 \rightarrow 3)-\beta$-Dglucan from yeast with a potential application as a plant growth promoter. International Journal of Biological Macromolecules, 165-170.

Sekiguchi, S. T. (2016). Suppression of macrophage-mediated phagocytosis of apoptotic cells by soluble $\beta$ glucan due to a failure of PKC-betaII translocation. İnternational Immuunopharmacology, 195-199.

Sima, P. V. (2018). $\beta$-glucans and cholesterol (Review). International Journal of Molecular Medicine, 17991808.

Stephen, A. C. (2017). Dietary fibre in Europe: current state of knowledge on definitions, sources, recommendations, intakes and relationships to health. Nutrition Research Reviews, 149-190.

Susan A. Joyce, A. K. (2019). The Cholesterol- Lowering Effect of Oat and Oat Beta Glukan: Modes of Action and Potential Role of Bile Acids and the Microbiome. Frontiers.

Şahin, G. (2018). Obez Kadınlarda Diyete Eklenen Yulaf Gevreğinin Vücut Ağırlığı Kaybına Ve Bazı Biyokimyasal Parametreler Üzerine Etkisi .

T.C. Resmi Gazete. Türk Gıda Kodeksi Beslenme ve Sağlık Beyanları Yönetmeliği. 26.01.2017. Sayı:29960, Gıda, Tarım ve Hayvancılık Bakanlığı, Ankara

Tessari, P., \& Lante, A. (2017). A Multifunctional Bread Rich in Beta Glucans and Low in Starch Improves Metabolic Control in Type 2 Diabetes: A Controlled Trial . Nutrients, 297.

Türkiye Halk Sağlığı Kurumu, S. B. (2015). Türkiye Kalp Ve Damar Hastalıkları Önleme Ve Kontrol Programı. Ankara.

Vetvicka, V. V. (2019). Beta Glucan: Supplement or Drug? From Laboratory to Clinical Trials. Molecules, 24(7),1251.

Visioli , F., \& Poli , A. (2019). Prevention and Treatment of Atherosclerosis: The Use of Nutraceuticals and Functional Foods. Handbook of Experimental Pharmacology, 1-15.

World Health Organization. (2019, 12 20). WHO: https://www.who.int adresinden alındı
X. Chen, K. S. (2014). Structure and properties of a $(1 \rightarrow 3)-\beta-D-$ glucan from ultrasound-degraded exopolysaccharides of a medicinal fungus. Carbonhydrate Polymers, 270-275.

Y. Ishimoto, K. I. (2018). Production of low-molecular weight soluble yeast $\beta$-glucan by an acid degradation method . International Journal of Biological Macromolecules, 2269-2278.

Z. Sun, H. Z. (2009). Sulfation of $(1 \rightarrow 3)-\beta$-D-glucan from the fruiting bodies of Russula virescens and antitumor activities of the modifiers. Carbonhydrate Polymers, 628-633.

Zhang, J. L. (2017). Impact of native form oat $\beta$-glucan on starch digestion and postprandial glycemia. Journal of Functional Foods, 73, 84 -90, 84-90.

Zhang, M. (2004). Carboxymethylated $\beta$-glucans from mushroom sclerotium of Pleurotus tuber-regium as novel watersoluble anti-tumor agent. Carbonhydrate Polymers, 319325 . 